ISSN: 0514-7336

DOI: http://dx.doi.org/10.14201/zephyrus2019833957

\title{
LOS CANTOS EPIPALEOLÍTICOS DE COVES DE SANTA MAIRA (ALICANTE): ESTUDIO FUNCIONAL A PARTIR DE LAS MARCAS DE USO Y DE LA EXPERIMENTACIÓN
}

\section{Epipalaeolithic pebbles from caves of Santa Maira site (Alicante): a functional study from the use-wear and the experimentation}

\author{
Margarita Vadillo Conesa*, Paula Jardón Giner** y J. Emili Aura Tortosa* \\ * Dpto. de Prehistoria, Arqueología e Historia Antigua. Facultad de Geografía e Historia. Univ. de Valencia. Avda. \\ Blasco Ibáñez, 28.46010Valencia.Correo-e: margarita.vadillo@uv.es; j.emili.aura@uv.es.ID ORCID: 0000-0001- \\ 6441-4921; 0000-0003-1074-4495 \\ ** Dpto. de Didáctica de las Ciencias Experimentales y Sociales. Univ. de Valencia. Facultad de Magisterio. Avda. \\ Tarongers, 4. 46022 Valencia. Correo-e: paula.jardon@uv.es. ID ORCID: 0000-0003-1542-7683
}

Recepción: 15/04/2018; Revisión: 14/11/2018; Aceptación: 7/12/2018

Resumen: En la Región Mediterránea ibérica resulta difícil encontrar estudios dedicados a los percutores-retocadores empleados en la producción lítica del Epipaleolítico. En este trabajo se presenta el estudio de 11 pequeños cantos localizados en coves de Santa Maira (Castell de Castells, Alicante), que fueron recuperados en los niveles epipaleolíticos, datados entre 13445 y 10195 años cal вр. Se trata de cantos rodados, aplanados y de tendencia alargada, en los que se han identificado diversas marcas. Están asociados a una numerosa industria lítica, dominada por láminas y laminitas, que permite relacionar los percutores y los sistemas de producción. En paralelo al estudio de las marcas de uso, se ha realizado un programa experimental cuyo objetivo era identificar los diferentes gestos empleados durante la talla y configuración de útiles retocados. La comparación entre los cantos arqueológicos y los experimentales muestra coincidencias en las marcas, en su posición y asociación. Estos resultados plantean que la hipótesis más probable de uso fue su empleo en diferentes fases de la producción lítica: desde la talla al retoque. Los paralelos encontrados en otros yacimientos peninsulares y del Mediterráneo occidental señalan que también pudieron intervenir en otras tareas, e incluso podrían haberse utilizado en actividades combinadas.

Palabras clave: Epipaleolítico; Región Mediterránea ibérica; percutores; retocadores; talla lítica.

АвSTRACT: In the Iberian Mediterranean region it is difficult to find studies dedicated to the percutors-touchers used in the lithic production of the Epipalaeolithic. This work presents the study of 11 small pebbles located in caves of Santa Maira (Castell de Castells, Alicante), which were recovered in the Epipaleolithic levels, dated between 13445 and 10195 years BP. These are rounded, flattened and elongated pebbles, in which various marks have been identified. They are associated with a numerous lithic industry, dominated by blades and little bladelets, which allows us to relate the hammerstones and the production systems. Parallel to the study of the use marks, an experimental programme has been carried out with the aim of identifying the different gestures used during the carving and configuration of retouched tools. The comparison between the archaeological and experimental pebbles shows coincidences in the marks, in their position and association. These results suggest 
that the most likely hypothesis of use was its use in different phases of lithic production: from carving to retouching. The parallels found in other peninsular and western Mediterranean sites indicate that they could also have been involved in other tasks, and could even have been used in combined activities.

Key words: Epipalaeolithic; Iberian Mediterranean Region; hammerstones; retouchoir; use-wear; flintworking.

\section{Introducción}

Los cantos rodados con diferentes marcas de uso suelen ser objetos poco estudiados, a pesar de que a menudo pueden ser la única evidencia de procesos de trabajo como el molido de diferentes sustancias orgánicas y minerales o la preparación de pieles y fibras, mientras que en otras ocasiones nos pueden ayudar a definir mejor las técnicas empleadas en el transcurso de la talla lítica (De Beaune, 1997; González e Ibáñez, 2002; Aura y Jardón, 2006; Adams et al., 2009; Cristiani et al., 2012; Dubreuil y Savage, 2014).

Este trabajo ${ }^{1}$ se centra en un conjunto de pequeños cantos encontrados en las excavaciones de coves de Santa Maira (Castell de Castells, Alacant). La observación de sus marcas, que incluyen piqueteados, estrías y desconchados, así como su po-

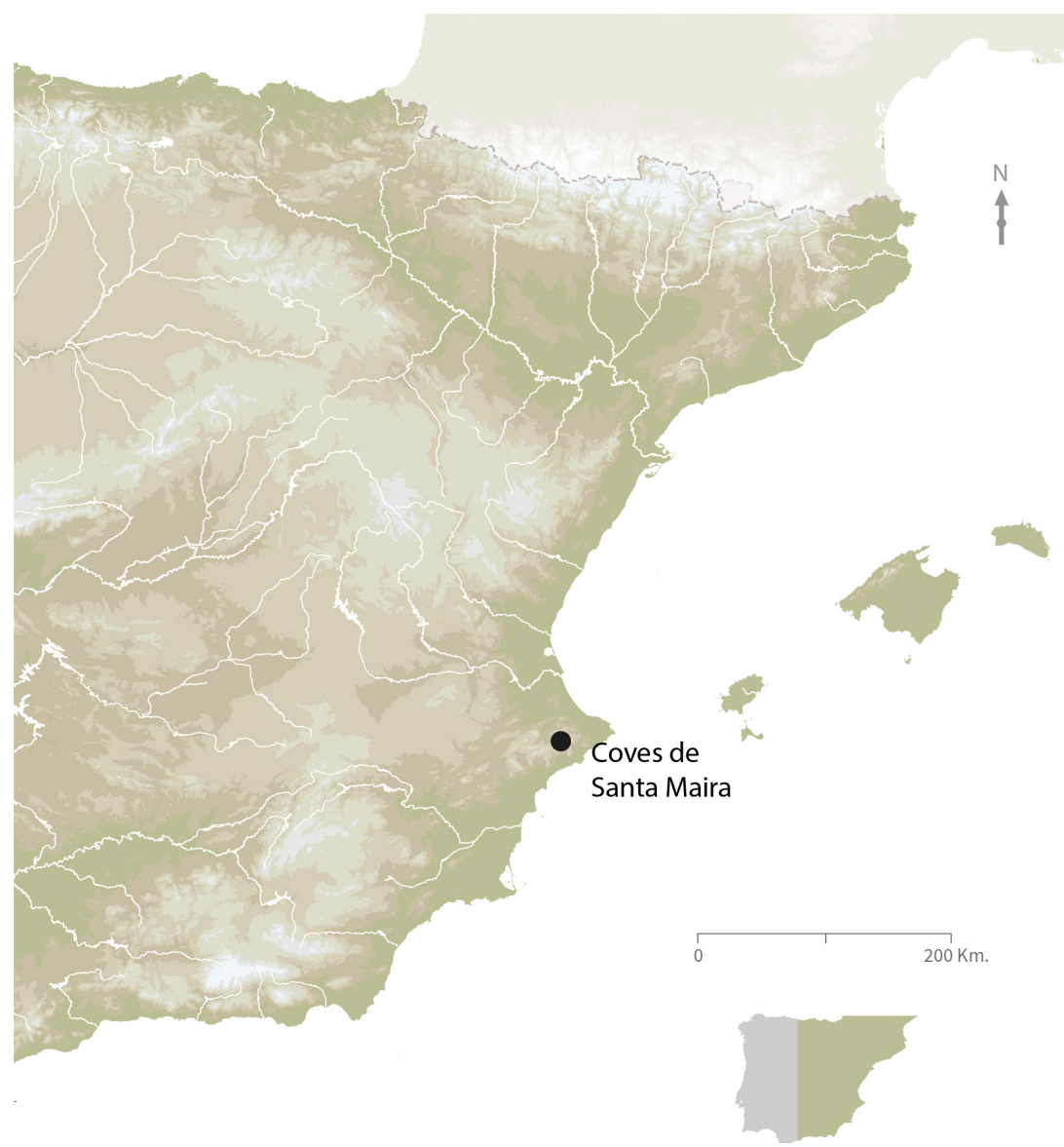

Fig. 1. Localización de coves de Santa Maira en la Región Mediterránea ibérica. sición sobre sus caras y lados, permiten plantear una hipótesis de partida: estos objetos han podido intervenir en actividades de talla, sirviendo como percutores-retocadores. Esta hipótesis enlaza sus marcas con las descritas en el estudio tecnológico de la industria lítica, permitiendo profundizar en la definición de las técnicas de talla empleadas para la producción de hojas/hojitas, que

1 Grupo de Investigación PREMEDoc. Esta investigación se ha realizado con fondos del Ministerio de Economía y Competitividad (LongTransMed: HAR2013-46861-R) y de la Generalitat Valenciana (AICO/2018/125).

son los soportes buscados para fabricar el utillaje configurado.

En el ámbito regional y con una cronología similar diversos autores han reconocido el uso del percutor blando, orgánico y mineral; el percutor duro, e incluso la percusión indirecta, siempre a partir de los estigmas de los productos de talla ${ }^{2}$. La

2 Vadillo, M.: Sistemes de producció lítica en el trànsit Plistocè-Holocè. Estudi de la seqüència arqueológica de Coves de Santa Maira (Castell de Castells, Alacant) i la seua contextualització mediterrània. Tesis doctoral inédita presentada en 2018 en la Univ. de Valencia. 
referencia regional sobre percutores no es numerosa, ya que los fabricados sobre hueso no son frecuentes, y sobre piedra, la referencia más cercana quizás se encuentra en los cantos descritos en Nerja (Aura y Jardón, 2006). En este caso podemos contrastar las marcas de los percutores y los estigmas de talla y si su asociación permite establecer un rasgo tecnológico regional.

La adopción de cualquier técnica de percusión y de un determinado método de talla supone una opción, una solución preferente frente a otras soluciones. Si estas decisiones se repiten y transmiten pueden dar lugar a tradiciones (Naudinot, 2010; Haudricourt, 1987). Sobre esta base se asienta la importancia de los estudios de las cadenas operativas y, en definitiva, de la tecnología lítica, ya que permite una aproximación a las tradiciones socioculturales de los grupos humanos de la Prehistoria. Por todo ello, consideramos que la muestra analizada resulta suficiente para testar la hipótesis inicial, ya que el objetivo es caracterizar las marcas que aparecen y asociarlas a acciones y materias trabajadas dentro de los procesos de producción de industrias líticas talladas, sin excluir que hayan podido participar en otros procesos de trabajo.

\section{El yacimiento y su secuencia}

El yacimiento de coves de Santa Maira se localiza en el término de Castell de Castells (Alicante), a unos $30 \mathrm{~km}$ de la costa actual. El yacimiento se ubica en un entorno de fuertes contrastes, a una altitud de $600 \mathrm{msnm}$.

La denominación del yacimiento incluye los dos sectores excavados hasta el momento: la boca oeste -SM-W- y el Corral del Gordo -CG-, que se sitúa en cotas más bajas. Los materiales estudiados en este trabajo provienen de SM-W, en cuya secuencia se identifican 5 grandes unidades litoestratigráficas. La Unidad sm-5 se formó durante GI-1 y constituye una sucesión de laminaciones apoyadas sobre una colada estalagmítica. Engloba las ocupaciones del Paleolítico Superior Final, identificando materiales característicos del Magdaleniense Superior y Final. La Unidad sM-4 se compone de arenas, gravas y pequeños bloques de piedra caliza de menos de $3 \mathrm{~cm}$. Su cronología indica que se depositó durante Gs-1 y el Preboreal. Contiene las ocupaciones epipaleolíticas, diferenciando en la base un Epipaleolítico microlaminar -EM- y a techo un Epipaleolítico sauveterroide -ES-. La Unidad sM-3 queda delimitada por grandes bloques, a muro y techo, y contiene los materiales mesolíticos. Por último, sM-2 engloba materiales neolíticos y la Unidad sM-1 contiene materiales de cronología diversa: de la Edad del Bronce, ibéricos y romanos, así como andalusíes (Aura et al., 2006; Aura, 2014).

Las piezas analizadas se concentran en un sector de algo más de $12 \mathrm{~m}^{2}$, pero no forman parte de un único episodio. Atendiendo a su distribución y posición estratigráfica es razonable pensar en al menos

\begin{tabular}{|c|c|c|c|c|c|c|c|c|}
\hline \multicolumn{9}{|c|}{ SANTA MAIRA- W } \\
\hline UNIDAD & FASE & LABORATORIO & Muestra & Proc. & $\begin{array}{c}\text { Data } \\
\text { C14 вр }\end{array}$ & $\begin{array}{c}\text { Cal вр } \\
\text { (95\% prob.) } \\
\end{array}$ & $\begin{array}{c}\text { Cal вс } \\
\text { (95\% prob.) }\end{array}$ & Referencia \\
\hline \multirow{3}{*}{4.1} & \multirow{3}{*}{$\begin{array}{l}\text { Epipaleolítico } \\
\text { 'sauveterroide' }\end{array}$} & Beta-156022 & Cervus elaphus & AMS & $9220 \pm 40$ & $10501-10258$ & $8552-8309$ & Aura et al., 2006 \\
\hline & & Beta-156021 & Vicia / Lathyrus & AMS & $9370 \pm 40$ & $10702-10500$ & $8753-8551$ & Aura et al., 2006 \\
\hline & & Beta-158014 & Quercus sp. & AMS & $9820 \pm 40$ & 11291-11181 & $9342-9232$ & Aura et al., 2006 \\
\hline \multirow{2}{*}{4.2} & \multirow{2}{*}{$\begin{array}{l}\text { Epipaleolítico } \\
\text { microlaminar }\end{array}$} & Beta-438705 & & AMS & $10830 \pm 40$ & $12774-12681$ & $10825-10732$ & Vadillo, 2018 \\
\hline & & Beta-149948 & Capra pyrenaica & AMS & $11590 \pm 70$ & $13559-13289$ & $11610-11340$ & Aura et al., 2006 \\
\hline \multirow[b]{2}{*}{5} & \multirow{2}{*}{$\begin{array}{l}\text { Magdaleniense } \\
\text { Superior final }\end{array}$} & Beta-156023 & Capra pyrenaica & AMS & $11920 \pm 40$ & $13944-13567$ & $11995-11618$ & Aura et al., 2006 \\
\hline & & Beta-471703 & Prunus sp. & AMS & $12320 \pm 30$ & $14535-14089$ & $12586-12140$ & Vadillo, 2018 \\
\hline
\end{tabular}

FIG. 2. Selección de dataciones disponibles para las ocupaciones del Magdaleniense Final y Epipaleolitico de Santa Maira-W. 
dos episodios de acumulación. El más antiguo -SM4.2 y contacto con SM5- está localizado en las cuadrículas más externas, mientras que el más reciente -SM-4.1- se sitúa en cuadrículas más interiores.

\section{Materiales y métodos empleados}

De los 11 objetos analizados 7 fueron recuperados en la Unidad SM-4 y por tanto se asocian a industrias epipaleolíticas. Otros 3 objetos fueron recuperados en contacto con el Magdaleniense Final -Unidad sM-5- y el restante en la base de sm3, tras la limpieza de una acción irregular. El lapso temporal que abarcan estos contextos según las dataciones radiocarbónicas sería 13445-10195 años cal вр (Aura, 2001; Aura et al., 2006; Vadillo, 2018).

El material estudiado fue guardado en bolsas independientes sin recibir ningún tratamiento químico ni mecánico. Se han analizado 11 cantos: 9 de caliza y 2 de esquisto; la mayoría están fragmentados. Su anchura se distribuye entre 17 y $34 \mathrm{~mm}$, mientras que su grosor se concentra entre 8 y 9,5 $\mathrm{mm}$, excepto una pieza que alcanza casi los $13 \mathrm{~mm}$ (Fig. 3). Por tanto, se trata de cantos con anchuras variables pero espesores similares, posiblemente seleccionados. En cuanto a su morfología, presentan formas alargadas, redondeadas en ambos extremos y de sección ovalada-aplanada.

Dos de los fragmentos (Fig. 3, n. ${ }^{\text {os }} 1$ y 10 ) formarían parte de una misma pieza, a pesar de que se

\begin{tabular}{|c|c|l|l|l|l|l|l|l|}
\hline N. & Cuadro & Unidad & $\begin{array}{c}\text { L } \\
(\mathrm{mm})\end{array}$ & $\begin{array}{c}\text { A } \\
(\mathrm{mm})\end{array}$ & $\begin{array}{c}\text { A } \\
(\mathrm{mm})\end{array}$ & $\begin{array}{c}\text { W } \\
(\mathrm{g})\end{array}$ & Material & Estado \\
\hline 1 & AA5 & 4.1 & 37,04 & 27,47 & 8,58 & 16,4 & caliza & fracturado \\
\hline 2 & AB4 & 4.2 & 27,5 & 22,57 & 8 & 8,5 & caliza & fracturado \\
\hline 3 & AA5 & $3 / 4.1$ & 26,27 & 29,31 & 12,81 & 13,8 & caliza & fracturado \\
\hline 4 & AB6 & 4.1 & 33,39 & 33,77 & 9,51 & 18,7 & caliza & fracturado \\
\hline 5 & AB3 & 4.1 & 31,68 & 25,76 & 8,15 & 9,4 & caliza & fracturado \\
\hline 6 & AA4 & 4.1 & 47,79 & 28,01 & 9,16 & 22 & caliza & fracturado \\
\hline 7 & AB4 & 4.2 & 41,04 & 33,8 & 9,52 & 22,9 & esquisto & fracturado \\
\hline 8 & AA3 & 4.2 & 64,58 & 17,36 & 8,71 & 16 & caliza & entero \\
\hline 9 & AB4 & $4.2 / 5$ & 77,15 & 30,2 & 9,47 & 38,2 & esquisto & entero \\
\hline 10 & AB4 & $4.2 / 5$ & 35,64 & 29,34 & 9,36 & 19,5 & caliza & fracturado \\
\hline 11 & AB4 & $4.2 / 5$ & 71,05 & 28,5 & 7,77 & 30,44 & caliza & fracturado \\
\hline
\end{tabular}

FIG. 3. Inventario de los materiales estudiados. han localizado en cuadros y capas diversas. El diferente estado de pátina y conservación que muestran nos estaría remitiendo a procesos postdeposicionales, sin que hayamos podido establecer el uso de alguna de las partes de la pieza una vez fracturada.

\subsection{Observación y descripción}

Para su estudio se ha utilizado una lupa binocular Nikon modelo smz-10, entre 0,66x y 4x. Para la realización de las fotografías en detalle se ha utilizado un microscopio Dino-Lite Digital Microscope AM711sMZT a 10x aumentos.

Con el fin de poder sistematizar la descripción de los cantos se ha creado una base de datos, que incorpora campos de las diferentes variables e incluye campos destinados al comentario de las primeras observaciones sobre la hipótesis de uso. La realización de la experimentación ha permitido contrastar esas observaciones y profundizar en la restitución del gesto vinculado a las diferentes marcas.

- En primer lugar, se han establecido criterios para la localización de las marcas distinguiendo las superficies mayores y planas, que hemos llamado caras A y в, y dentro de cada una se han distinguido la parte proximal, medial y distal, siempre que la pieza estuviera entera. Se ha considerado como cara A aquella que ofrece más evidencias de marcas de trabajo que hemos descrito como zonas de uso o "unidades morfo-funcionales". A los

laterales de estas caras los hemos llamado lateral 1 y lateral 2 , distinguiendo asimismo la parte proximal, medial y distal. Por último, para describir la presencia-ausencia de marcas en el extremo estricto, se ha reservado el término "extremidad", y en caso de que la pieza apareciera entera se ha diferenciado entre extremidad proximal y distal. 
- Todas las piezas rotas con marcas en la superficie, en el extremo o en los bordes, han sido consideradas como fragmentos distales o mesodistales, según las dimensiones conservadas en relación con las reconstruidas.

- En cuanto al tipo de marcas, se ha distinguido entre tres grupos: estrías, piqueteados y levantamientos o desconchados. Entendemos por estrías aquellas marcas tanto longitudinales como transversales compuestas por raspados de recorrido corto, siempre de escasa profundidad. Por piqueteados entendemos una asociación de puntos de impacto, que producen pérdida de materia, poco profundos, de dimensiones reducidas y muchas veces asociados a estrías cortas. Por último, los levantamientos serían extracciones menores que aparecen en los bordes de los cantos, quizás relacionables con la presión sobre la materia prima tallada.

- Los soportes son pequeños cantos planos y redondeados en los que resulta difícil establecer el origen natural o antrópico de algunos pulidos. En ausencia de estrías orientadas no se ha tenido en cuenta este tipo de marcas en el análisis de las piezas.

- Para definir la acción se han considerado criterios como la repetición e intensidad de las marcas y el grado de modificación de la superficie. Esto podría estar ligado a tres variables: 1) la litología, 2) la naturaleza del material trabajado y 3) la energía invertida en la acción (o la repetición temporal de la misma acción en la zona). El reconocimiento de la superficie que ocupan las marcas puede ser relevante para identificar acciones y su posible secuencia temporal.

- Para reconocer el gesto, se han observado la invasión y la delimitación de las marcas, con el fin de determinar si la acción está focalizada en una zona concreta o bien invade otras áreas. La orientación de las marcas resulta fundamental para determinar el uso de la pieza y el recorrido que seguiría el gesto, aunque determinar el origen ha sido complicado. Con todo esto hemos explorado las posibles acciones en las que se ha utilizado cada pieza y su trayectoria.
- No existen marcas que indiquen el golpeo intencional destinado a la fracturación de las piezas, por tanto, la rotura de las piezas sería consecuencia del uso de las mismas, lo cual conllevaría su abandono.

\subsection{Protocolo experimental}

La realización de la experimentación surge por la necesidad de comprobar nuestra hipótesis inicial, basada en el contexto en el que han sido recuperados los objetos y en la similitud de su morfología y sus marcas con otros ejemplares arqueológicos que plantean un uso como percutores-retocadores (De Beaune, 1989, 1997). Los cantos utilizados en la experimentación son de caliza, esquisto y sílex, recogidos en la misma cuenca del yacimiento. Para la experimentación se eligieron aquellos que, por morfología, dimensiones y litología, se asemejan macroscópicamente a los ejemplares arqueológicos.

Se ha elaborado un protocolo experimental que supone la recopilación de datos generales, comunes en muchos trabajos, como materia prima, tecnología utilizada en el uso y tipología de la pieza (Cristiani et al., 2012), añadiendo a los anteriores el tipo de prensión de la misma y la descripción del tipo de acción concreta para la que se ha utilizado. Para la descripción de la acción hemos distinguido entre la determinación del gesto y el resultado final de la misma, es decir, las marcas consecuencia de la utilización con un determinado fin y empleando un gesto determinado. También hemos incorporado un campo relacionado con las fracturas y el abandono de las piezas experimentales, puesto que buena parte de las piezas arqueológicas están fracturadas.

El tipo de sílex utilizado, a nivel macroscópico se puede describir como un sílex cretácico de estructura homogénea y de grano fino, que proviene del sistema prebético, y que coincide en cuanto a características macroscópicas y procedencia con el que aparece en la secuencia de coves de Santa Maira ${ }^{3}$. Con el objetivo de reproducir la talla laminar se ha

3 Vadillo, op. cit. n. 2. 
recurrido a una talladora experimentada, y se han utilizado para el registro del proceso varias cámaras fotográficas, así como una cámara de vídeo. De esta manera se realiza un registro individualizado de cada acción específica y es posible efectuar ulteriores comprobaciones.

\section{Resultados}

La observación detallada de las huellas visibles en los cantos permitió establecer la hipótesis de uso ya planteada: su intervención como percutores-retocadores en la talla y configuración del utillaje laminar/microlaminar. A partir de la misma, se diseña la realización de una experimentación como un medio adecuado para su contraste, permitiendo avanzar en su modificación, descarte o aceptación.

\subsection{Descripción de las marcas de los materiales arqueológicos}

Las marcas más comunes identificadas son las estrías y los piqueteados, en muchos casos asociadas. Es posible, por tanto, que estén vinculadas al desarrollo de una misma acción. Estas marcas se sitúan tanto en las caras planas, siempre en una posición cercana a los extremos, como en los laterales. Los desconchados también aparecen, pero con una menor incidencia, siempre acompańados por las estrías y los piqueteados.

En algunos casos la incidencia de las marcas en la superficie de los cantos es mínima, lo que podría vincularse a una fracturación del canto en los momentos iniciales a su utilización. Sin embargo, en otros cantos se aprecia una utilización intensa tanto por la incidencia de las marcas como por la presencia de unas depresiones importantes en las caras.

En las caras planas hemos podido comprobar la repetición de ciertos patrones en la dirección de las estrías. En los casos en que se puede distinguir su recorrido, se observa una delineación oblicua respecto al eje longitudinal de la pieza, y siempre con la misma orientación, que hemos establecido como
NW-SE (Fig. 4, n. ${ }^{\text {os }}$ 1, 2, 4 y 5; Fig. 5, n. ${ }^{\text {os }} 7$ y 9-11). En otras piezas, estas estrías aparecen asociadas a los piqueteados, formando una maraña de marcas en la que es imposible distinguir su recorrido. Otro rasgo que se repite en las marcas que aparecen en las caras planas es la desviación de todas ellas hacia la extremidad derecha del canto. Menos frecuentes son los desconchados, que siempre aparecen asociados a las marcas de las caras planas y que se sitúan en los bordes derechos (Fig. 4, n. ${ }^{\text {s }} 5$ y 9 ).

En los laterales hemos distinguido también los dos tipos de marcas, estrías y piqueteados, que aparecen de manera aislada, o bien combinándose ambos tipos. Respecto a la orientación que siguen las estrías en los casos en que la distinción de este aspecto ha sido posible, se observa una delineación este-oeste, es decir, se desarrollan de manera transversal al eje longitudinal de la pieza. A veces su extensión no se circunscribe únicamente al lateral, sino que se extienden hacia alguna de las caras o hacia las dos (Fig. 4, n. ${ }^{\circ}$ 4). En uno de los cantos (Fig. 4, n. ${ }^{\circ}$ ) aparecen estrías laterales que siguen un recorrido longitudinal, aunque estas son escasas y aparecen de manera somera. Las características de marcas en los laterales parecen remitir a una menor recurrencia en el uso de estas zonas, debido a su menor incidencia en la superficie de la pieza.

Respecto a las marcas que encontramos en los extremos, se han distinguido piqueteados aislados, que en alguna pieza forman concavidades y que se extienden invadiendo las caras de los cantos (Fig. 4, n.o 4). Estos piqueteados se muestran también combinados con las estrías, que aparecen con orientaciones diversas. En uno de los cantos (Fig. 4, n. ${ }^{\circ}$ 6) aparece, en la extremidad que conserva, una serie de levantamientos bifaciales que la configuran con una morfología apuntada, pero no aparecen marcas de uso que indiquen una utilización específica relacionada con esta morfología. Aparecen, no obstante, algunas estrías que seguirían la delineación del perfil de la extremidad de la pieza. Con todo ello presuponemos que los levantamientos serían consecuencia de la fracturación, bien por un uso reiterado del canto, bien por la intensidad de la misma acción. 

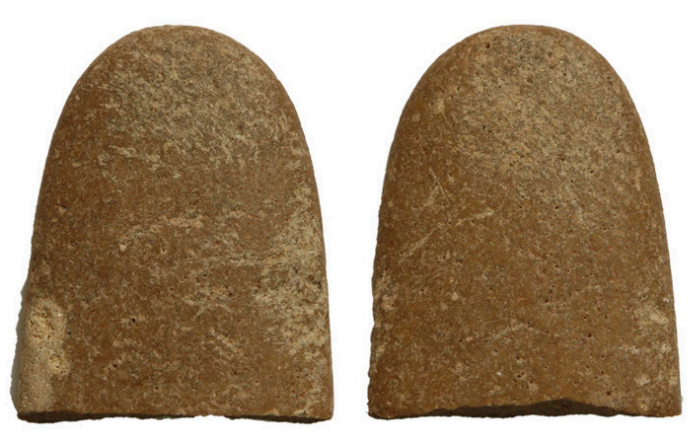

1

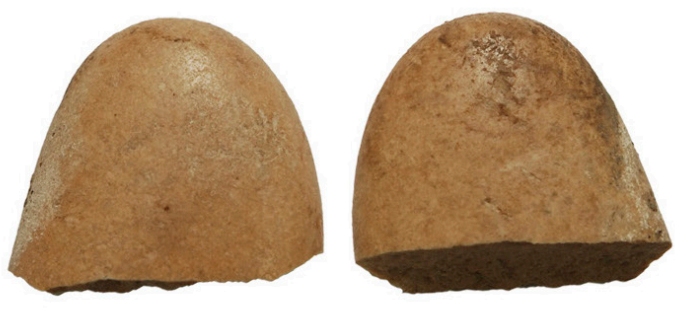

3
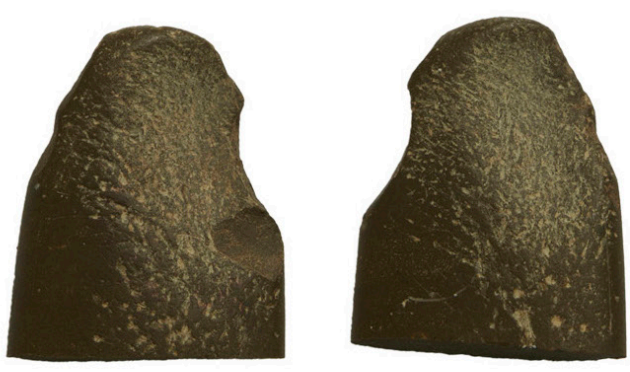

5
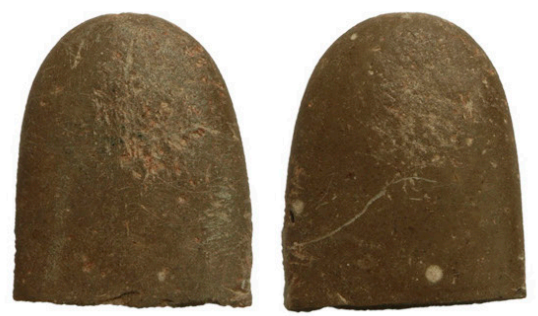

2
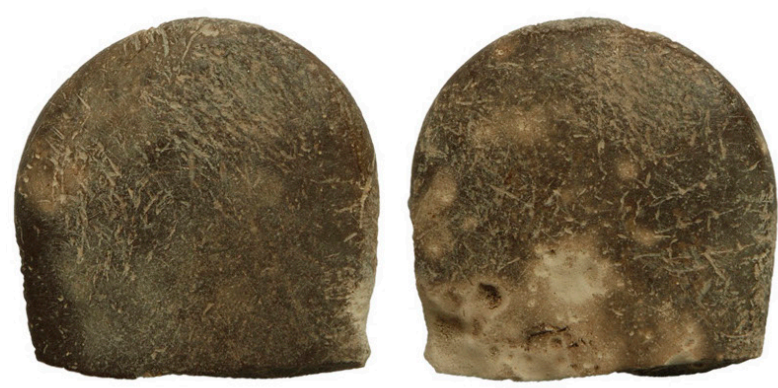

4
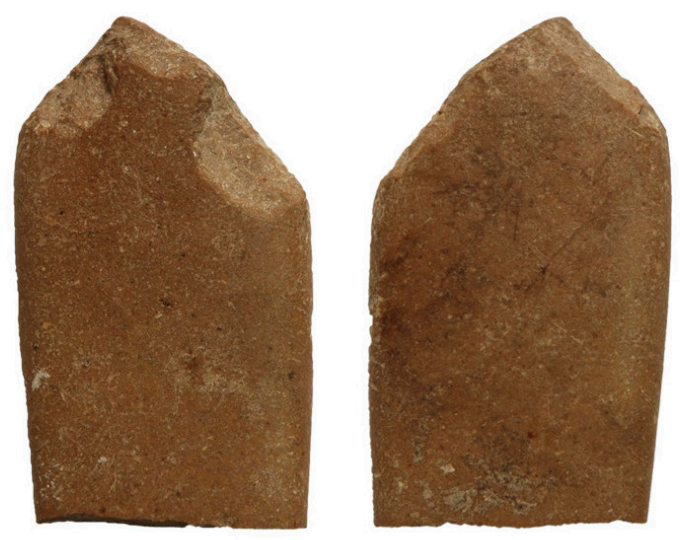

6

0

FIg. 4. Percutores-retocadores de Santa Maira-W; la numeración se corresponde con la de la Fig. 3.

Debido al tipo de marcas y a su recurrencia, la hipótesis de uso propuesta es que las piezas estuvieron vinculadas al proceso de talla lítica. Las diferentes zonas de uso en las que aparecen las marcas no estarían vinculadas a un uso destinado a tareas de diferente índole, sino que estas variaciones corresponderían a los diferentes tipos de prensión del canto: de manera perpendicular al bloque de materia a trabajar, que generaría las marcas en las caras de las piezas; de manera paralela o uso lateral de los 

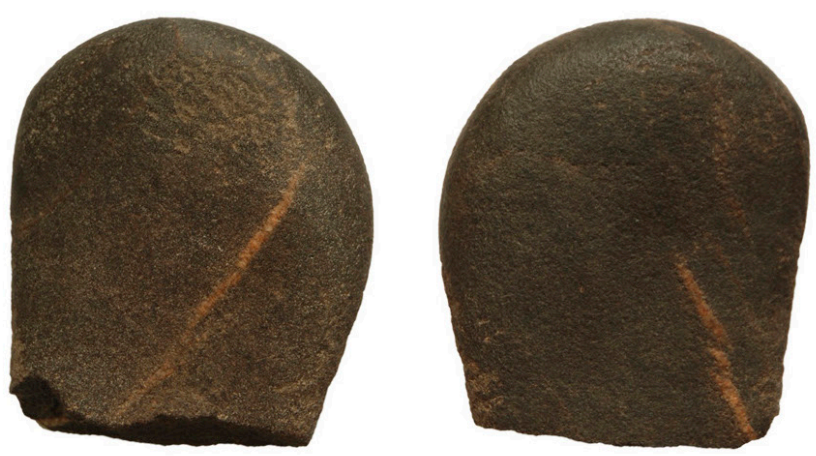

7
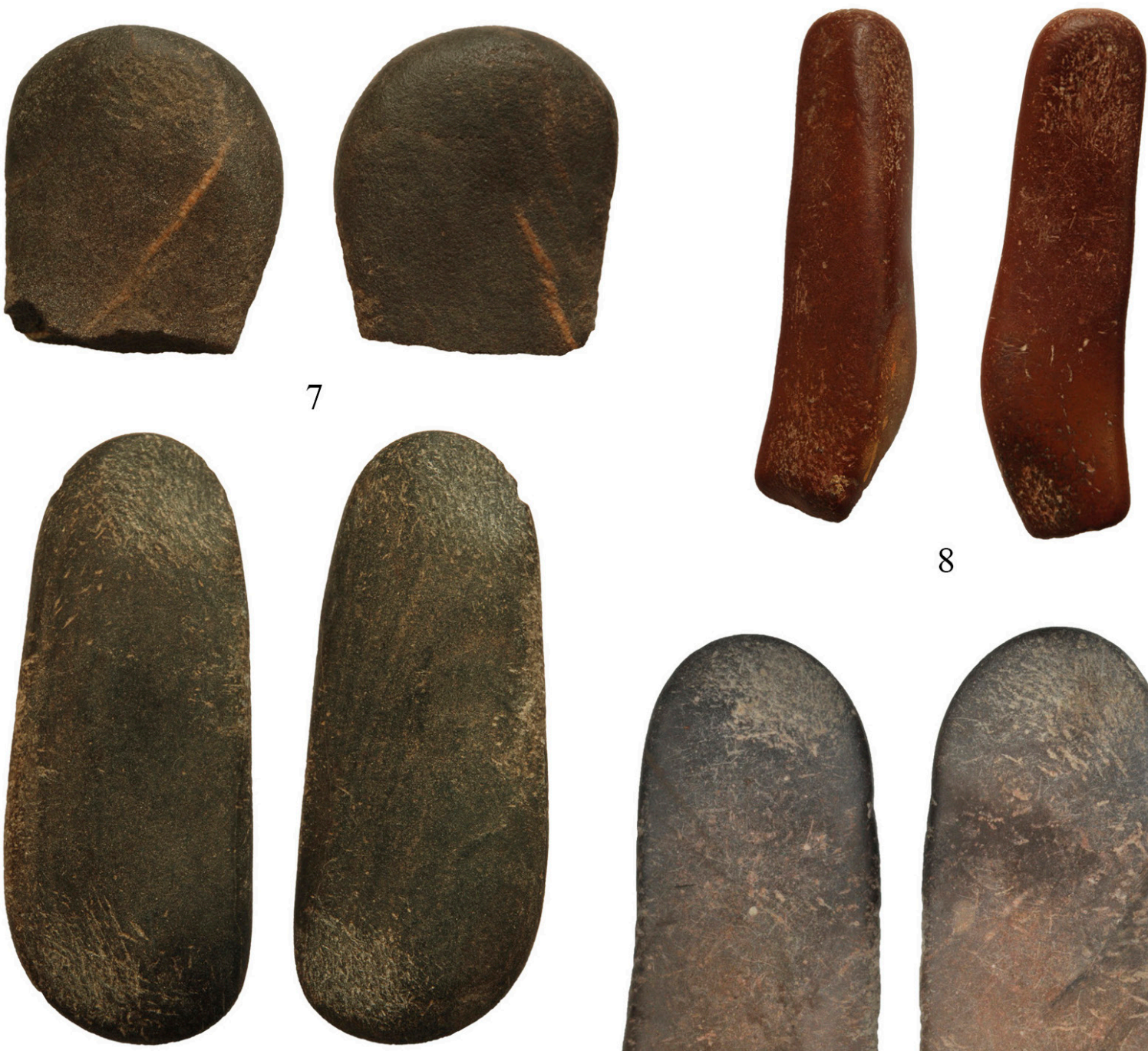

8
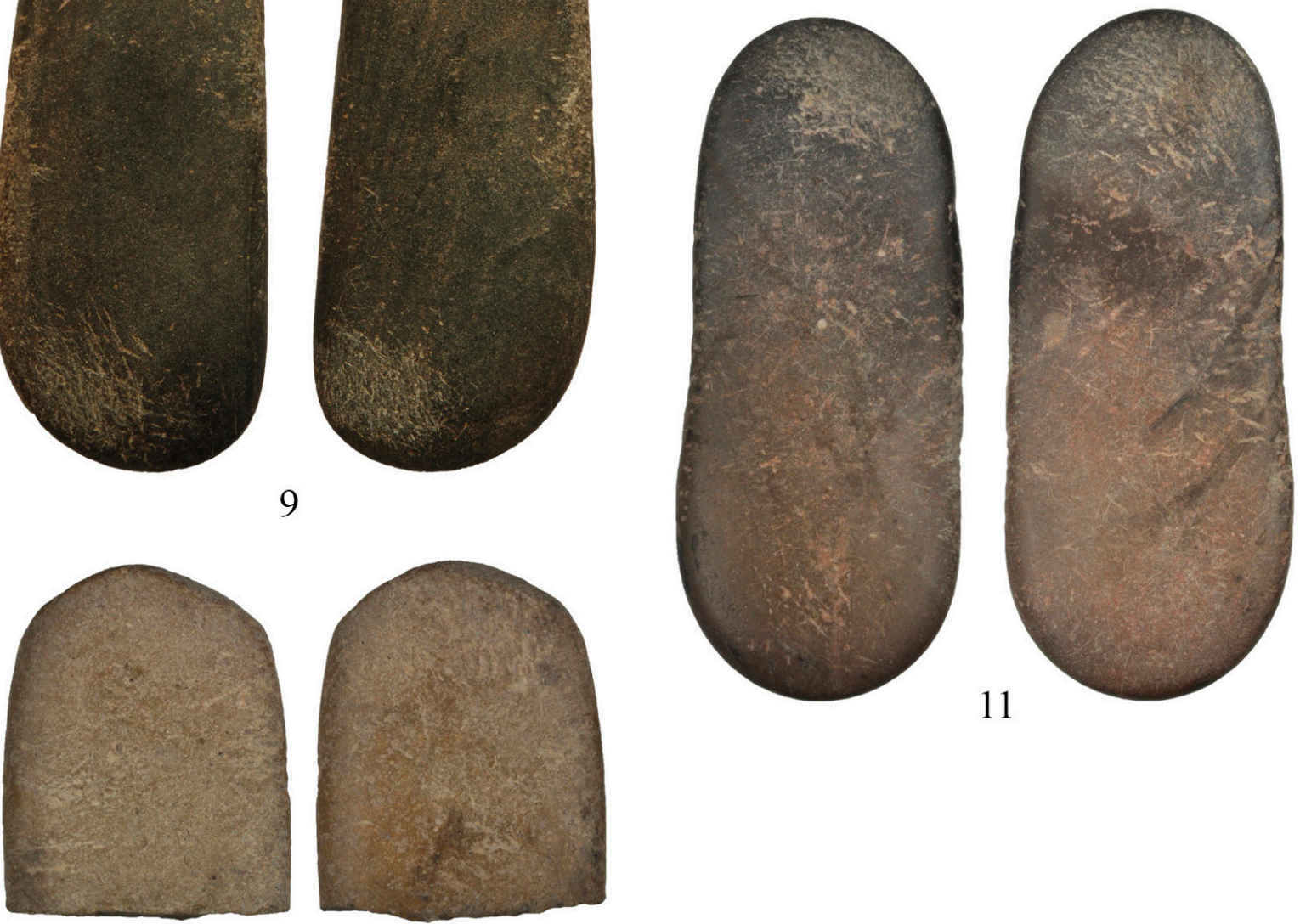

10

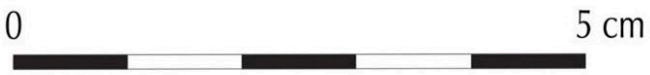

FIG. 5. Percutores-retocadores de Santa Maira-W; la numeración se corresponde con la de la Fig. 3. 


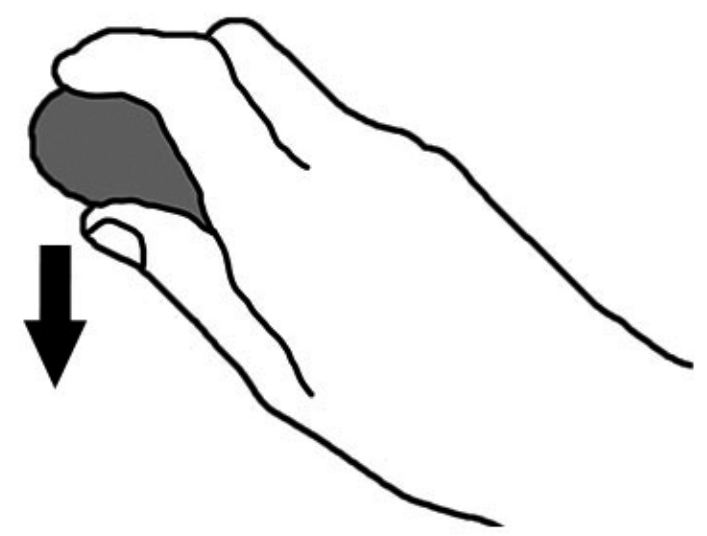

a

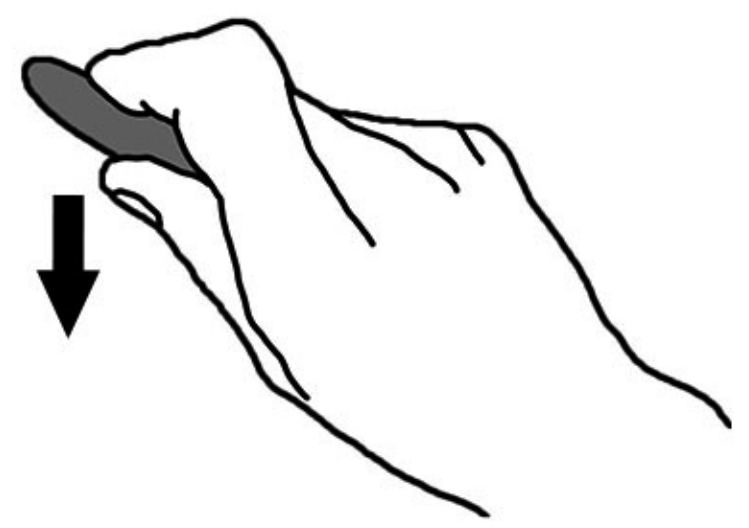

b

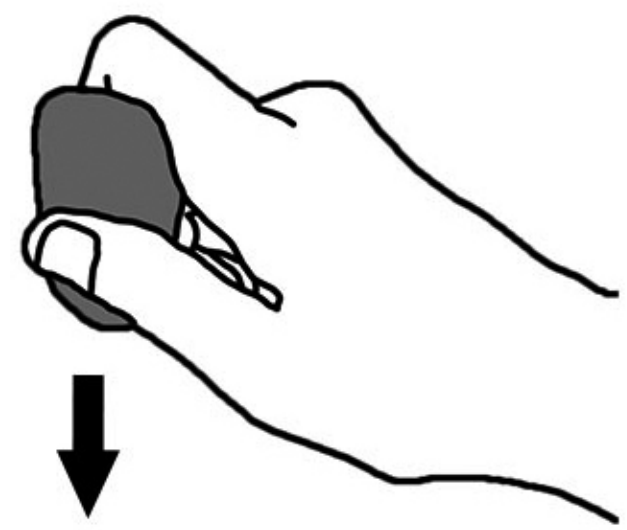

C

Fig. 6. Hipótesis de sujeción de los cantos y dirección de los movimientos generados en la ejecución de la acción. cantos, que supondría la alteración de los laterales, o bien siguiendo el mismo eje longitudinal, una acción que incidiría en las extremidades de las piezas (Fig. 6).

Estas piezas podrían entrar en la categoría de percutores minerales blandos, que utilizados mediante percusión directa generan unas características en los talones (Pelegrín, 2000) que han sido reconocidas en los soportes laminares/microlaminares de los niveles epipaleolíticos de Santa Maira.

\subsection{Las producciones liticas talladas asociadas}

Hemos considerado necesaria una aproximación a la industria lítica de los niveles en los que quedan englobados los cantos ya que partimos de la hipótesis de que existe una estrecha relación de los cantos con la talla lítica.

En los niveles epipaleolíticos de coves de Santa Maira aparece una industria lítica sobre sílex procedente en su mayoría del ámbito local, en torno a un $50 \%$ en el nivel más antiguo y prácticamente un $80 \%$ en el más reciente, y en menor medida del ámbito regional (9-30\%). Existen asimismo otros tipos minoritarios, que apenas alcanzan un $2 \%$. El porcentaje restante lo conformarían aquellas piezas en las cuales, debido a las alteraciones térmicas o a la similitud entre tipos, no se ha podido determinar el tipo concreto. Se trata, en general, de un sílex de calidad media o buena que se encuentra en nódulos, procedentes de conglomerados y lechos fluviales, advirtiéndose una selección de los nódulos de pequeño tamaño.

El análisis tecnológico de la industria lítica epipaleolítica indica variabilidad en la explotación de los volúmenes, pero un objetivo común: la producción de laminitas destinadas principalmente a ser configuradas como armaduras. Aparecen matices en las explotaciones registradas en cada episodio, EM y ES, pero en ambos casos se observan desarrollos sobre la superficie ancha del volumen, así como otros más envolventes, en los cuales se explotarían los laterales, mientras que en otros casos la explotación se centraría en las superficies estrechas (Fig. 7). Aparecen 

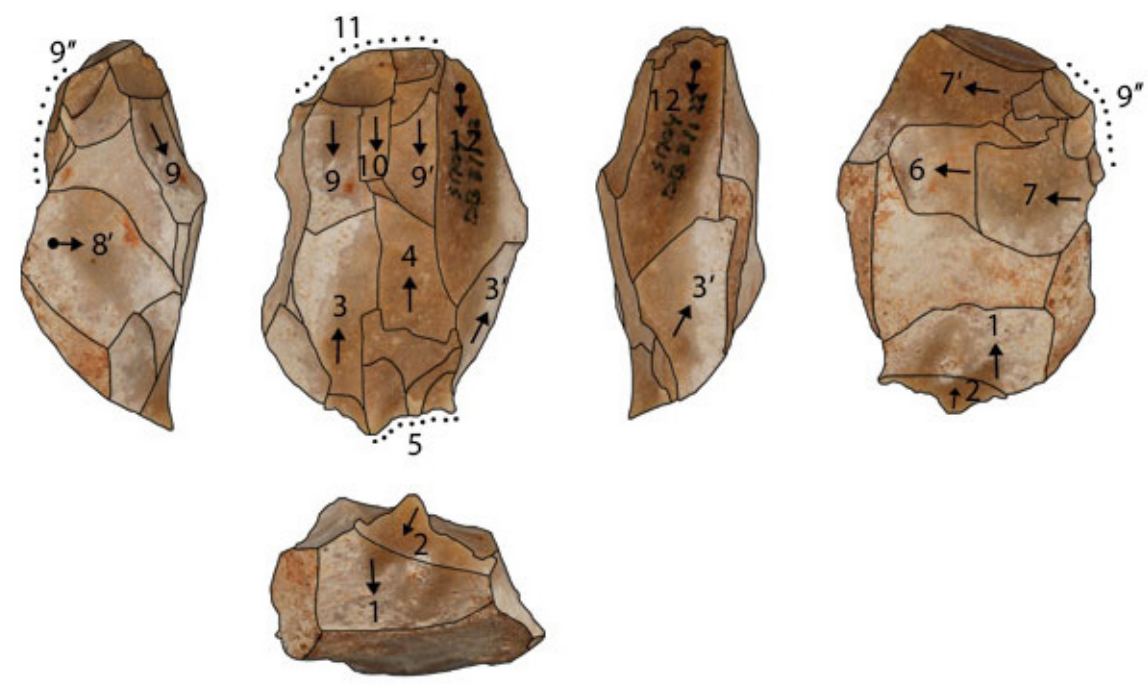

1
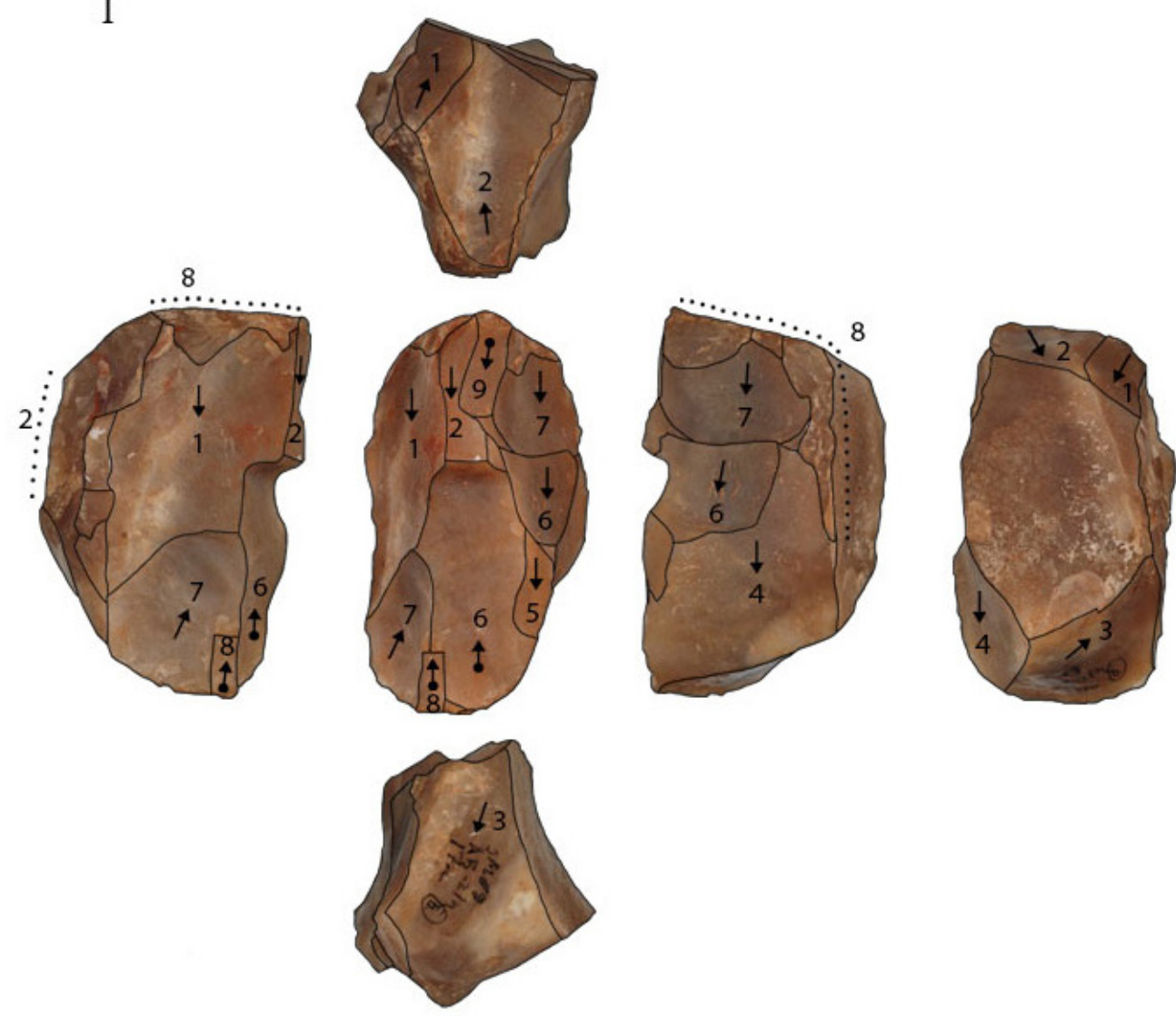

2

0

$5 \mathrm{~cm}$

Fig. 7. Núcleos de coves de Santa Maira: 1) sobre cara ancha y 2) sobre cara estrecha. 

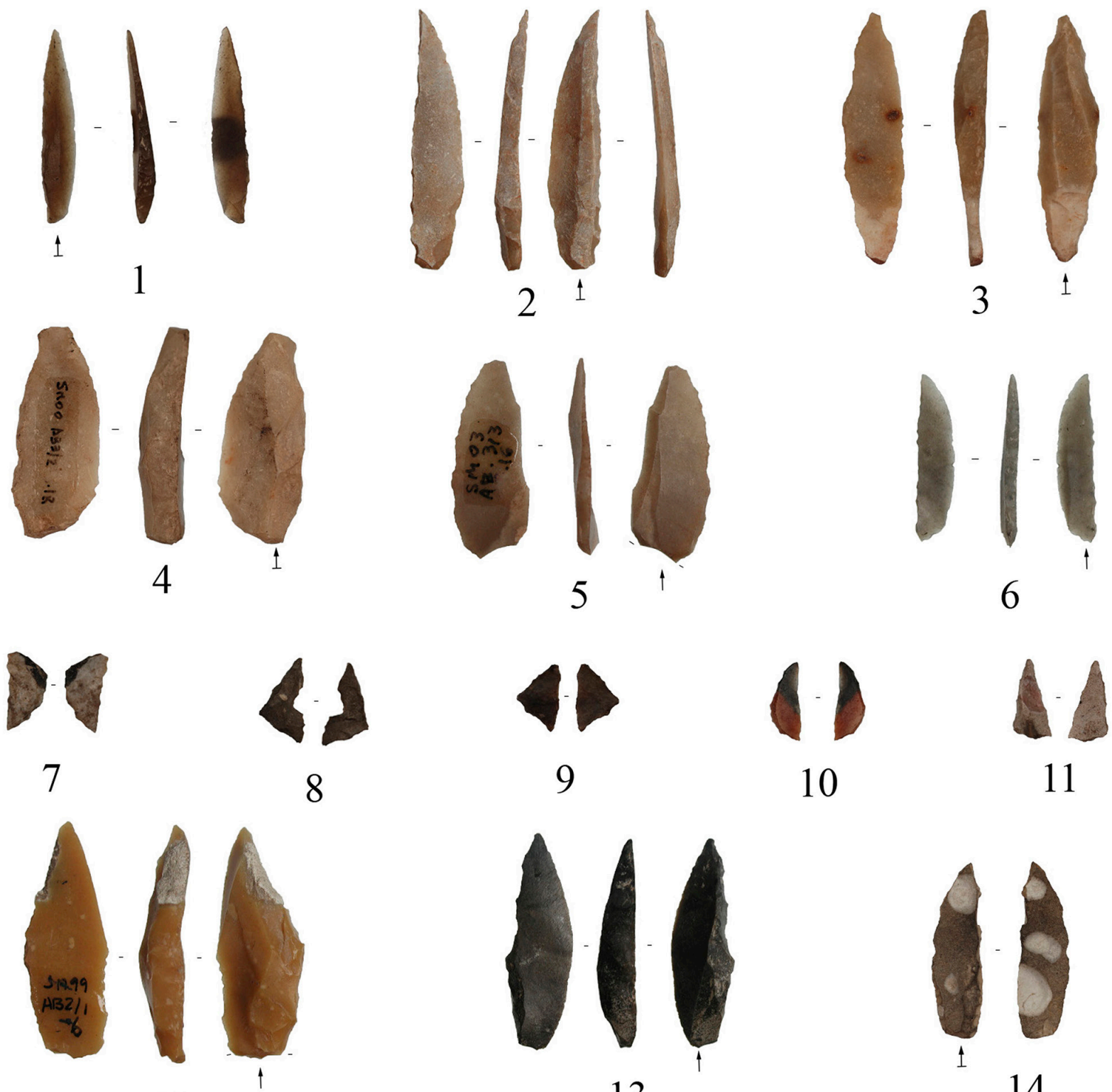

8

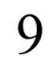

10

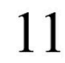

12

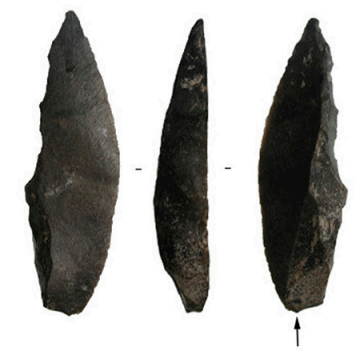

13

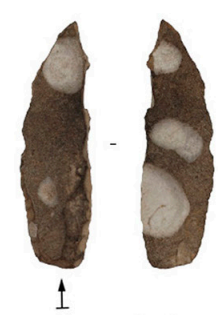

14

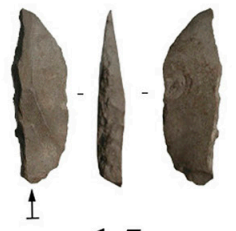

15
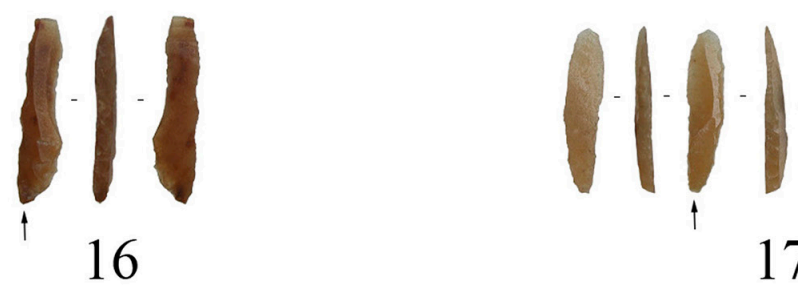

17

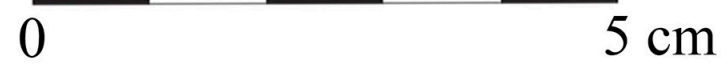

FIG. 8. Armaduras de coves de Santa Maira: 1-6) Epipaleolitico microlaminar; 7-17) Epipaleolitico sauveterroide. 
dinámicas unidireccionales y bidireccionales, siendo las primeras las más abundantes. En cuanto a la gestión durante el proceso de talla, se distinguen diversas acciones para el mantenimiento tanto de la carena como de la convexidad en los laterales en el caso de explotaciones envolventes, o bien aquellas destinadas a su eliminación en el caso de las explotaciones sobre superficies planas. Se aprecia asimismo el desarrollo de diversas acciones de mantenimiento del plano de percusión, desde pequeñas extracciones hasta la eliminación de todo el plano de percusión para la creación de uno nuevo ${ }^{4}$.

Los soportes de plena talla tienen unas dimensiones muy pequeñas, gran parte de ellos tienen una longitud media de unos 20-21 mm, y una amplitud media entre los 7 y $8 \mathrm{~mm}$, mientras que su espesor medio estaría entre 1,5 y $2 \mathrm{~mm}$. La tendencia a la búsqueda de laminitas de pequeñas dimensiones, regulares y en la mayoría de los casos centrales, se da a lo largo de toda la secuencia epipaleolítica. Los estigmas proximales relacionados con las técnicas de percusión ha sido descrito ampliamente por Pelegrin (2000). Siguiendo sus propuestas, se ha diagnosticado que la técnica empleada para su extracción sería mayoritariamente la percusión mineral blanda. La abrasión o preparación de la zona del proximal, un talón de dimensiones reducidas y un bulbo poco prominente nos permitirían reconocer esta técnica en los soportes laminares.

En cuanto al utillaje configurado, durante el Epipaleolítico las armaduras superan el 50\% del total de útiles retocados. Entre ellas aparecen laminitas de dorso abatido y puntas de dorso rectilíneo (Fig. 8). La principal diferencia entre ambos momentos reside en la importancia que adquieren los geométricos dentro de la fase es (Fig. 8). El grupo de los raspadores es el segundo grupo más representado en ambos momentos, mientras que las truncaduras, también presentes de forma significativa en ambos momentos, en la fase sauveterroide experimentan un acusado descenso respecto a la fase microlaminar.

4 Vadillo, op. cit. n. 2.

\subsection{Los resultados de la experimentación}

En la experimentación se han utilizado 16 cantos rodados de origen marino (Fig. 9), con unas dimensiones, una morfología y unas características litológicas similares a las de los arqueológicos (Fig. 10). Por lo que respecta a la materia prima, 14 son de piedra caliza, uno de sílex y otro de esquisto. El sílex utilizado se corresponde con las materias primas mayoritarias que se identifican en los niveles epipaleolíticos. Con todo ello se han llevado a cabo diferentes acciones vinculadas a procesos que se desarrollarían en diferentes momentos de la cadena operativa, utilizando técnicas diversas (Fig. 11):

\begin{tabular}{|c|c|c|c|c|c|}
\hline N.o & $\begin{array}{c}\mathrm{L} \\
(\mathrm{mm})\end{array}$ & $\begin{array}{c}\mathrm{A} \\
(\mathrm{mm})\end{array}$ & $\begin{array}{c}\mathrm{E} \\
(\mathrm{mm})\end{array}$ & $\begin{array}{c}\mathrm{W} \\
(\mathrm{g})\end{array}$ & $\begin{array}{c}\text { MATERIA } \\
\text { PRIMA }\end{array}$ \\
\hline 1 & 85,09 & 33,92 & 14,02 & 70,8 & caliza \\
\hline 2 & 66,4 & 24,39 & 8,55 & 26,8 & caliza \\
\hline 3 & 74,9 & 30,8 & 11,94 & 51,3 & esquisto \\
\hline 4 & 83,85 & 31,97 & 10,67 & 52 & caliza \\
\hline 5 & 85,08 & 30,89 & 11,82 & 47,2 & caliza \\
\hline 6 & 66,11 & 26,53 & 13,17 & 35,5 & caliza \\
\hline 7 & 52,27 & 32 & 9,07 & 50,1 & caliza \\
\hline 8 & 64,82 & 21,48 & 19,15 & 52,6 & sílex \\
\hline 9 & 58,59 & 28,46 & 13,24 & 35,2 & caliza \\
\hline 10 & 52,5 & 24,22 & 7,06 & 14,8 & caliza \\
\hline 11 & 65,44 & 30,95 & 15,8 & 47,8 & caliza \\
\hline 12 & 55,85 & 36,51 & 11,36 & 37,6 & caliza \\
\hline 13 & 59,19 & 20,55 & 9,09 & 20 & caliza \\
\hline 14 & 74,27 & 33,67 & 13,4 & 25,5 & caliza \\
\hline 15 & 68,33 & 31,66 & 15,47 & 49,7 & caliza \\
\hline 16 & 81,59 & 34,74 & 17,32 & 71,9 & caliza \\
\hline
\end{tabular}

Fig. 9. Descripción de los percutores-retocadores experimentales.

1) Preparación de la cornisa del núcleo:

- Percusión: acciones de preparación de las extracciones. Este tipo de preparación es característica de las percusiones con percutor mineral blando. Hemos reproducido el acondicionamiento de la cornisa del núcleo en los núcleos experimentales, y como consecuencia en los cantos han aparecido estrías y piqueteados en las caras planas.

Zephyrus, LXXXIII, enero-junio 2019, 39-57 

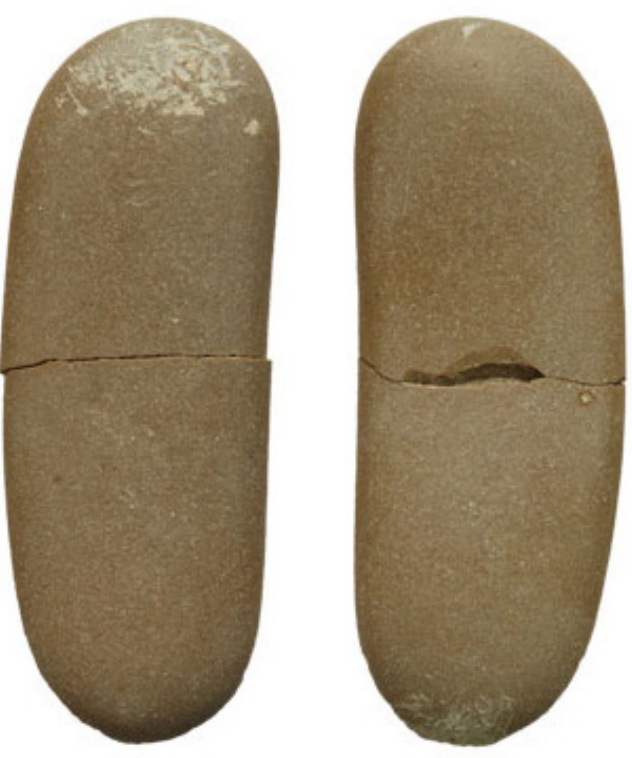

\section{PE2}
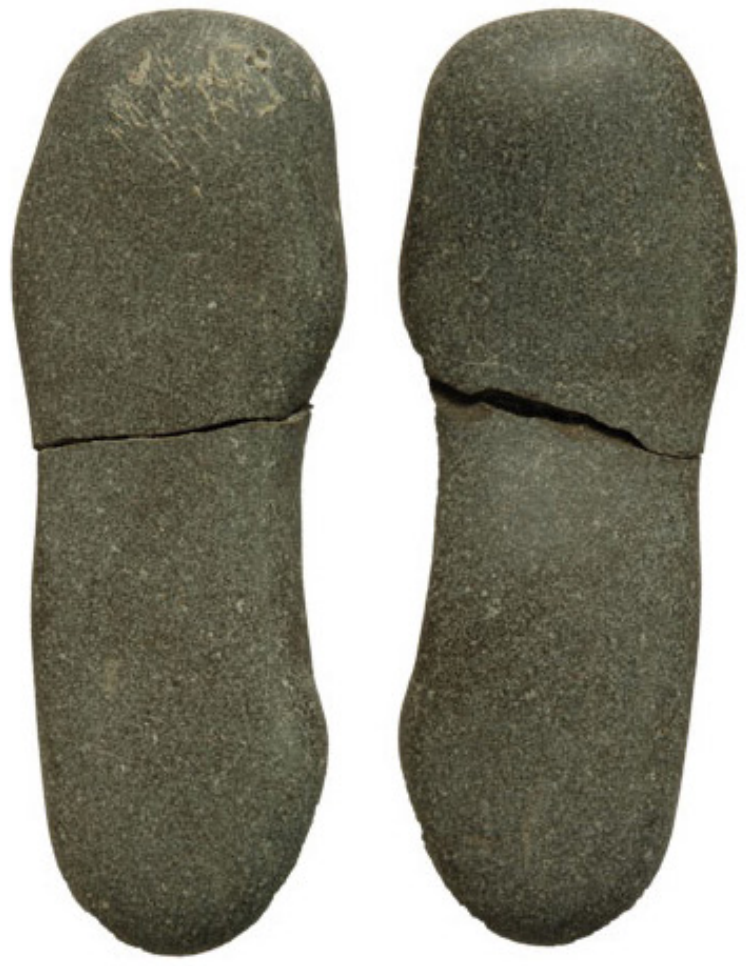

PE5
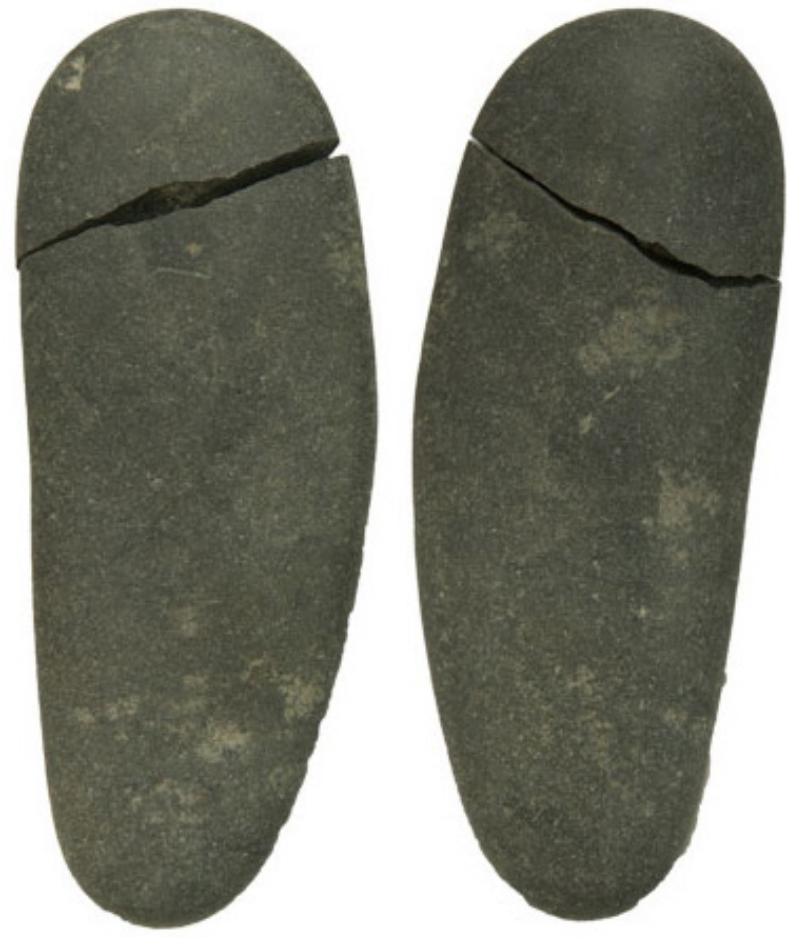

\section{PE4}
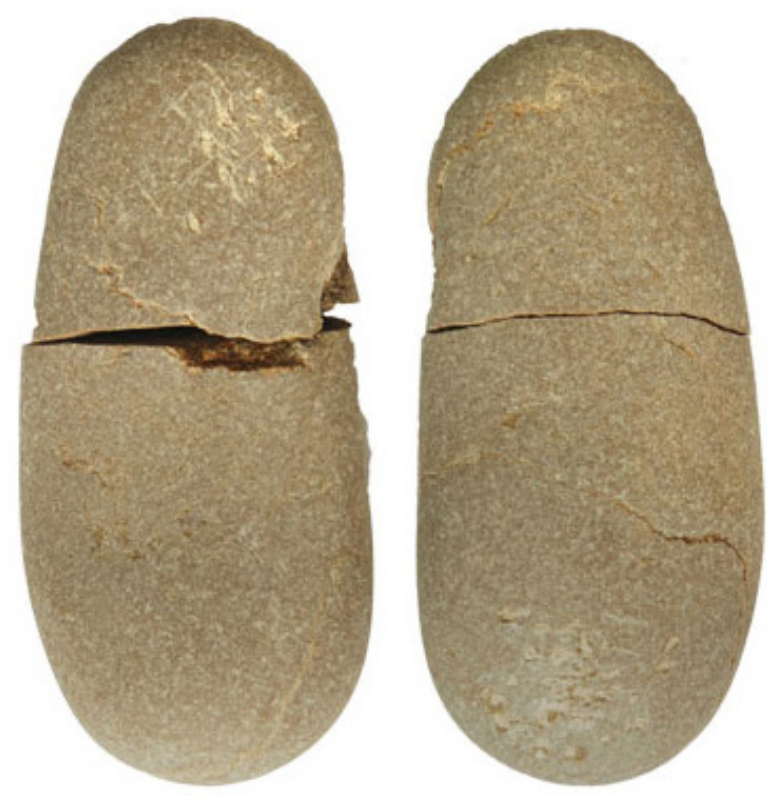

\section{PE15}

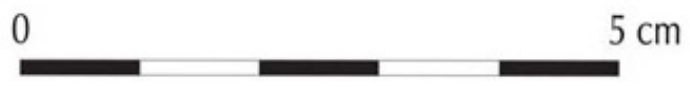

Fig. 10. Cantos experimentales n. ${ }^{\circ s}$ 2, 4, 5 y 15 . 


\begin{tabular}{|c|c|c|c|}
\hline Acción & Овјетіvo & RESULTADO DE LA ACCiÓN & LOCALIZACIÓN \\
\hline percusión & extracción de soportes & piqueteado & cara \\
\hline percusión & preparación de la cornisa y extracción de soportes & incisiones y piqueteados & cara \\
\hline presión & preparación de la cornisa & incisiones & extremidad \\
\hline percusión & extracción de soportes & levantamientos & cara \\
\hline percusión & preparación del núcleo y extracciones & piqueteado & extremidad \\
\hline percusión & $\begin{array}{l}\text { preparación de la cornisa, gestión del núcleo y extracción } \\
\text { de soportes }\end{array}$ & incisiones y piqueteados & cara \\
\hline percusión & extracción de soportes & incisiones, piqueteados y levantamientos & cara \\
\hline presión & preparación de la cornisa & incisiones & cara \\
\hline abrasión & retoque de laminitas & incisiones & lateral \\
\hline percusión & preparación del núcleo & levantamientos & extremidad \\
\hline percusión & retoque de lasca & piqueteado & extremidad \\
\hline abrasión & retoque de laminitas & incisiones & cara y lateral \\
\hline percusión sobre yunque & retoque de raspador & incisiones y piqueteados & extremidad \\
\hline percusión & retoque de raspador & incisiones & cara \\
\hline percusión & extracción de soportes & incisiones y piqueteados & cara \\
\hline presión & retoque de lasca & incisiones & lateral \\
\hline percusión & extracción de soportes & piqueteado & cara \\
\hline percusión & extracción de soportes & incisiones y piqueteados & cara \\
\hline percusión & extracción de soportes & incisiones y piqueteados & cara \\
\hline pieza durmiente & extracción de soportes & incisiones y piqueteados & cara \\
\hline
\end{tabular}

FIG. 11. Acciones, objetivos y marcas de los percutores-retocadores experimentales con su localización indicada.

- Presión: con la misma finalidad anterior, es decir, realizar preparaciones en la cornisa de los núcleos, se ha utilizado una técnica diferente, con el objetivo de observar el tipo de marcas que generaría la presión en el proceso de eliminación de las imperfecciones de la cornisa. Como consecuencia, han aparecido estrías en aquellas zonas del canto utilizadas en la ejecución de dicha acción, en este caso la extremidad de un canto y la cara plana de otro.

2) Preparación y gestión del núcleo. Dentro de esta categoría hemos englobado diferentes dinámicas que tendrían como objetivo mantener la morfología adecuada del núcleo.

- Percusión: empleada, por ejemplo, en la extracción de soportes para la regularización de la superficie de talla, debido a la aparición de accidentes o bien con la finalidad de reorganizar el proceso de talla. En el desarrollo de esta técnica se han utilizado, sobre todo, los extremos de diferentes cantos, lo cual ha creado piqueteados aislados, que en ocasiones también se muestran combinados con las estrías. Asimismo, han aparecido levantamientos como consecuencia de estas acciones.

- Abrasión: utilizada en diversas acciones de acondicionamiento del núcleo, sobre todo para rebajar las aristas vivas. Esto crea estrías sobre los percutores, que habrían sido utilizados en sus caras planas.

3) Extracción de productos:

- Percusión: en algunas piezas se identifican piqueteados aislados que en otras aparecen combinados con estrías. También se aprecian levantamientos en los bordes de los cantos, bien de manera aislada, bien combinados con las marcas descritas. Se han utilizado en la ejecución de esta tarea tanto las caras planas como sus extremos.

- Percutor durmiente: esta técnica se basaría en el golpeo del volumen contra el canto, 
que permanecería inmóvil sostenido con una mano. Esta acción genera estrías y piqueteados en las caras utilizadas con esta finalidad.

4) Retoque de los soportes:

- Percusión: utilizada en el retoque para la configuración de raspadores. Esta acción genera piqueteados aislados, o bien estrías aisladas, tanto en las caras planas como en las extremidades.

- Presión: la presión encaminada al retoque de los productos ha dado lugar a la aparición de estrías en los cantos. Para el desarrollo de esta técnica se ha utilizado el lateral de un canto.

- Abrasión: debido al tamaño de las laminitas se ha intentado un retoque del dorso mediante abrasión, generando en las caras y laterales de los percutores una serie de estrías.

- Percusión sobre yunque. Esta técnica se basa en la introducción de un elemento sobre el que reposaría el bloque de sílex, como puede ser un soporte de origen mineral, el suelo o cualquier otro elemento con una superficie apta para el apoyo del material a tallar o retocar. En el caso concreto que exponemos se ha utilizado un soporte mineral. El objetivo en el desarrollo de esta técnica era la configuración del frente de un raspador. Utilizando para ello la extremidad de un canto, se han generado en esta zona estrías y piqueteados.

$\mathrm{Al}$ realizar las diversas tareas, hemos constatado la relativa fragilidad de los cantos, ya que en la mayoría de los casos se ha producido su fracturación sin haberlos utilizado de forma intensa o repetida.

\section{Discusión}

Existe un creciente interés por los macroútiles no tallados, en contextos arqueológicos diversos, que van desde el Paleolítico medio hasta el Neolítico y en contextos geográficos variados (De Beaune, 1997; Adams et al., 2009; Dubreuil y Savage, 2014). En este trabajo se ha analizado un conjunto de cantos rodados de características bastante homogéneas: sección plano-convexa, tendencia alargada y dimensiones reducidas, si los comparamos con el resto de útiles no tallados.

Objetos similares se reconocen en yacimientos neandertales del Macizo Central francés y en Esquilleu (Cantabria), relacionados con la talla Quina; se trata de cantos algo más espesos, anchos y pesados (Raynal et al., 2012: fig. 4; Nebot, 2007). En los contextos gravetienses de Istúritz, De Beaune (1989) advierte la presencia de marcas bien delimitadas sobre las caras planas y extremos, que en algunos casos llegarían a formar una depresión desplazada hacia la derecha. Estas piezas son definidas como Enclume type Isturitz, considerando que jugarían un rol pasivo, utilizadas como soporte o yunque. En una revisión posterior, De Beaune (1997) los define como compresseurs y, a partir de la experimentación, propone su uso hipotético como maillets -martillos-. Estos cantos serían utilizados como percutores mediante la técnica de percusión lanzada indirecta, así entrarían en contacto con útiles intermedios para el trabajo de diferentes materias.

En el ámbito mediterráneo, se ha descrito este tipo de cantos, con estrías y piqueteados, en la cueva de Nerja (Málaga) y en Hoyo de la Mina (Málaga). En el caso de Nerja, se han asociado a diferentes usos, como percutores para la talla lítica o la fracturación de huesos (Aura y Jardón, 2006) y martillos (Márquez, 2005). En uno de los cantos de la cueva de Nerja se observa una decoración figurativa que se ha identificado como un ave, mientras que en la otra cara se observarían líneas y trazos que recorrerían toda la cara (Márquez, 2005). Para Hoyo de la Mina no disponemos de descripciones de las marcas, aunque sí de una propuesta de uso como alisadores en el trabajo del hueso, o bien un uso como retocadores utilizando la técnica de la presión (Such, 1920). En otros yacimientos de la vertiente mediterránea peninsular existen referencias a retocadores y percutores, adscritos a niveles del final del Paleolítico superior, Epipaleolítico y Mesolítico (Barandiarán, 2001; Casabó, 2004; Gilabert et al., 2012); no obstante, resulta dificil establecer su relación con los objetos aquí estudiados en ausencia de un estudio funcional. 
En el $\mathrm{N}$ peninsular se han analizado este tipo de piezas en Lumentxa, Laminak II, Santa Catalina y Santimamiñe, con cronologías entre 12000-10000 BP, que se corresponderían con el Magdaleniense Superior y el Aziliense (González e Ibáñez, 2002). En este estudio pionero se reconocen marcas de abrasión y estrías, que son interpretadas como consecuencia de un movimiento de frotación vinculado con el trabajo de la piel con adición de ocre. Los autores advierten sobre la multifuncionalidad que pudieron tener estas piezas, que en muchas ocasiones podría ser inadvertida por las escasas marcas originadas en algunos trabajos. El estudio individualizado de los cantos de Santimamiñe (Delgado-Raack, 2011) incide en esta posible multifuncionalidad de las piezas.

Fuera ya del ámbito peninsular, De Beaune (1997) publica un largo listado de yacimientos franceses con presencia de cantos que entrarían dentro de la categoría de compresseurs y que abarcarían una amplia cronología. Algunos de ellos aparecen en niveles del tránsito Pleistoceno-Holoceno y se corresponderían con las características morfológicas de los cantos aquí estudiados. Otros autores los consideran como percutores en acciones de percusión indirecta (González e Ibáñez, 2002; De Beaune, 1997), en las que se utilizarían útiles intermedios como perforadores, buriles o láminas no retocadas para el trabajo de diferentes materias como hueso, marfil, conchas, madera o piel. Se ha demostrado, a partir de la experimentación, que la configuración cóncava de las zonas de piqueteado se puede asociar al uso como percutor golpeando una pieza lítica a modo de cincel para tallar la madera (Jardón et al., 2018: figs. 1 , n. ${ }^{\circ} 3$ y 3 , n. ${ }^{\circ} 1$ ). Incluso se ha propuesto una utilización de estas técnicas para la elaboración de arte mueble (De Baune y Buisson, 1996).

En algunos yacimientos del $\mathrm{N}$ de Italia aparecen este tipo de piezas, en Terlago (Cristiani y Dalmeri, 2011), Riparo Dalmeri (Cristiani et al., 2012), Bus de la Lum (Peresani et al., 1999-2000) o Abris Vilabruna (Aimar et al., 1992), en todos los casos en contextos de las últimas fases del Epigravetiense. Los estudios no presentan el mismo nivel de detalle, pero las piezas de Terlago y Riparo Dalmeri han

(C) Universidad de Salamanca sido interpretadas como pulidores vinculados al proceso de trabajo de la piel, con adición de ocre (Cristiani et al., 2011). Algunas de las marcas son similares a las descritas, pero la identificación puntual de restos de ocre -en las caras, no en los lateralesen los cantos aquí estudiados podría estar originada por la presencia frecuente de restos de ocre en los sedimentos. En el caso de las pieza de Bus de la Lum y Abris Villabruna su uso se relacionaría con trabajos de la talla y el retoque de útiles líticos.

La amplia distribución geográfica de estos cantos se evidencia con su aparición en las costas del sur del Mediterráneo, en territorio de Argelia, en los niveles iberomauritanos del yacimiento de Tamar Hat (Sari, 2005). Se trata de piezas con marcas de uso identificadas como puntiformes y estrías lineares, que se concentrarían preferentemente en las dos caras y en los dos extremos, apuntándose a su uso como percutores o como retocadores.

\section{Conclusiones}

En los cantos de coves de Santa Maira se aprecia una selección en cuanto a su morfología y dimensiones. Se trata de cantos rodados, planos, relativamente pequeños y con los extremos redondeados. Respecto a la materia prima, su selección posiblemente estuvo ligada a la disponibilidad en el entorno. A pesar de su reducido tamaño, son efectivos como percutores para la producción de industrias de pequeñas dimensiones, que requieren aplicar un control ajustado de fuerza y dirección.

Los resultados obtenidos tras su análisis permiten establecer que se usaron como percutores minerales blandos, mediante percusión directa, generando las características descritas en numerosos trabajos. Estas características han sido reconocidas en los talones de los soportes laminares/microlaminares de los niveles epipaleolíticos de Santa Maira. Además, al ser utilizados en otras tareas, como la preparación del núcleo y el retoque, se ha observado que las marcas no difieren respecto de las generadas durante la extracción de soportes. Por tanto, a pesar de que todas las marcas remiten a tareas vinculadas con la talla lítica, no podemos diferenciar su separación 
en tareas concretas. Una reflexión similar se ha planteado por parte de Barandiarán y Cava para los cantos de Aizpea, reconociendo la dificultad de distinguir entre percutores y retocadores, ya que, a pesar de su pequeño tamaño, estos bien habrían podido haber servido como percutores atendiendo al tamaño de las industrias asociadas. Este hecho también ha sido señalado en otros conjuntos microlaminares como en el caso de Tamar Hat. Las diferentes técnicas utilizadas en el desarrollo de las acciones, percusión, presión y abrasión, pudieron generar marcas diferentes, pero su interpretación resulta compleja cuando se produce sobre las mismas áreas. De este modo, no podemos determinar si la pieza se utilizaría en el desarrollo de las acciones empleando una sola o combinando varias de ellas.

Durante la experimentación hemos comprobado la facilidad de fracturación de las piezas al emplear la técnica de la percusión, por tanto, podemos suponer que esta podría ser la causa de que los cantos de Santa Maira se encuentren en gran medida en este estado. Una cualidad también observada en otros estudios, pero sin que podamos descartar procesos postdeposicionales.

El hecho de haber reconocido y comprobado la acción relacionada con las marcas ha permitido conocer de forma detallada las marcas que genera el proceso. Un elemento en común de los cantos de Santa Maira con otras de las piezas referenciadas es el hecho de que las marcas se centran mayoritariamente en las caras, en una posición oblicua o desviada hacia la derecha, lo que podemos entender que implica la ejecución de gestos concretos que generan esta orientación. En ocasiones se aprecia un uso reiterado, que provoca una concavidad importante en la zona (Fig. 4, n. ${ }^{\circ}$ 5). Esta concavidad, asociada a la orientación, también puede indicar un uso como percutor intermedio para talla de otros materiales -madera o hueso-, como se ha demostrado experimentalmente. Un elemento cualitativo sobre el uso de estos objetos es la decoración que algunos presentan, así como su asociación a una sepultura en el caso de Grotta della Ferrovia. Estos datos remiten a un uso intensivo y a un nivel de aprecio y consideración que se nos escapa.
Se han descrito diversas propuestas de uso, vinculadas a las características y componentes de cada yacimiento -trabajo de la piel, percutores-retocadores para la industria lítica, etc.-. En el caso de coves de Santa Maira sabemos que participaron en los sistemas de producción lítica. Si participaron en otros procesos relacionados con el trabajo de otras materias, las evidencias habrían quedado enmascaradas por las generadas por la talla o resultan por ahora indistinguibles. Así pues, cabe plantearse que estos objetos pudieron ser versátiles, interviniendo en diferentes acciones, pero que en nuestro caso están vinculados con la talla de soportes laminares-microlaminares.

\section{Bibliografía}

Adams, J.; Delgado, S.; Dubreuil, L.; Hamon, C.; Plisson, H. y Risch, R. (2009): "Functional analysis of macro-lithic artefacts: a focus on working surfaces". En Sternke, F.; Eigeland, L. y Costa, L.-J. (eds.): Non-Flint Raw Material Use in Prehistory. Old prejudices and new. Proceedings XV World Congress International Union for Prehistoric and Protohistoric Sciences, 11, Session C77. Oxford: Archaeopress, pp. 43-66.

Aimar, A.; Alciati, G.; Broglio, A.; Castelletti, L.; Cattani, L.; D’Amico, C.; Giacobini, G.; Maspero, A. y Peresani, M. (1992): "Les Abris de Villabruna dans la Vallée du Cismòn", Preistoria Alpina-Museo Tridentino di Science Naturali, 28, pp. 227-254.

Aura, J. E. (2001): "Cazadores emboscados. El Epipaleolítico en el País Valenciano". En Villanverde (ed.): De Neandertales a Cromañones. El inicio del poblamiento humano en tierras valencianas. Valencia: Univ. de Valencia, pp. 219-238.

Aura, J. E.; Carrión, Y.; García Puchol, O.; Jardón, P.; Jordá, J. F.; Molina, Ll.; Morales, J. V.; PasCuAl, J. Ll.; Pérez Jordá, G.; Pérez Ripoll, M.; Rodrigo, M. J. y Verdasco, C. (2006): "Epipaleolítico-Mesolítico en las comarcas centrales valencianas". En Alday, A. (ed.): El Mesolítico de muescas y denticulados en la cuenca del Ebro y el litoral mediterráneo ibérico. Memorias de yacimientos alaveses, 11. Vitoria: Diput. Foral Álava, pp. 65-118.

Aura, J. E. y Jardón, P. (2006): “Cantos, bloques y placas. Macroutillaje de la Cueva de Nerja (ca. 1200010000 вр). Estudio traceológico e hipótesis de uso". 
En Sanchidrián, J. L.; Márquez, A. M. y Fullola, J. M. (eds.): IV Simposio de Prehistoria Cueva de Nerja. La cuenca mediterránea durante el Paleolítico superior 38000-10000 años. Reunión de la VIII Comisión del Paleolitico Superior UISPP. Nerja: Fund. Cueva de Nerja, pp. 284-297.

Barandiarán, I. (2001): "Otros manipulados de piedra”. En Barandiarán, I. y Cava, A. (coords.): Cazadores-recolectores en el Pirineo navarro: el sitio de Aizpea entre 8000 y 6000 años antes de ahora. Vitoria-Gasteiz: UPV, pp. 149-178.

Casabó, J. (2004): Paleolítico superior final y Epipaleolitico en la Comunidad Valenciana. Alicante. Serie Mayor, 3. Alicante: MARQ.

Chavaillon, J. (1979): "Essai pou une typologie du matériel de percussion", Bulletin de la Société Préhistorique Française, 76 (8), pp. 230-233.

Cristiani, E. y Dalmeri, G. (2011): "Functional analysis of the decorated ground stone tool from Terlago (TN)", Preistoria Alpina, 45, pp. 185-191.

Cristiani, E.; Lamorini, C. y Dalmeri, G. (2012): "Ground stone tool production and use in the Late Upper Palaeolithic: The evidence from Riparo Dalmeri (Venetian Prealps, Italy)", Journal of Field Archaeology, 37 (1), pp. 34-50.

De Beaune, S. A. (1989): "Essai d'une classification typologique des galets et plaquettes utilisés au Paléolithique”, Gallia Préhistoire, 31, pp. 27-64.

De Beaune, S. A. (1992): "Une lacune à combler: l'étude des galets utilisés au Paléolithique", Les Nouvelles de l'archéologie, 47, pp. 48-52.

De Beaune, S. A. (1997): Les galets utilisés au Paléolithique Supérieur. Approche archéologique et expérimentale. Gallia Préhistoire Suppl. xxxire. Paris: CNRS.

De Beaune, S. A. y Buisson, D. (1996): "Différenciation spatio-chronologique de l'utilisation des galets au cours du Paléolithique supérieur pyrénéen: les cas d'Isturitz (Pyréenées- Atlantiques) et de La Vache (Ariège)". En Delporte, H. y Clottes, J. (dirs.): Pyrénées préhistoriques, arts et sociétés. Paris: Comité des Travaux Historiques et Scientifiques, pp. 129-142.

Delgado-Raack, S. (2011): "La utilización de cantos rodados y plaquetas en la secuencia estratigráfica de Santimamiñe", Kobie, Serie Excavaciones Arqueológicas en Bizkaia, 1, pp. 171-196.

Dubreuil, L.; Savage, D.; Delgado-Raack, S.; Plisson, H.; Stephenson, B. y De la Torre, I. (2015): "Current Analytical Frameworks for Studies of UseWear on Ground Stone Tools". En Marreiros, J.
M.; Gibaja, J. F. y Ferreira, N. (eds.): Use wear and Residue Analysis in Archaeology. Serie Manuals in Archaeological Method, Theory and Technique. Springer International Publishing. Berlin, pp. 115-158.

FORTEA, J. (1973): Los complejos microlaminares y geométricos del Epipaleolítico mediterráneo español. Salamanca: Univ. de Salamanca.

Gilabert, X.; Martínez-Moreno, J. y Mora, R. (2012): "Pitted stone cobbles in the Mesolithic site of Font del Ros (Southeastern Pre-Pyrenees, Spain): some experimental remarks around a controversial tool type", Journal of Archaeological Science, 39, pp. 1587-1598.

González Urquijo, J. E. e Ibáñez, J. J. (2002): “The use of pebbles in Eastern Vizcaya between 12000 and 10000 вр”. En Procopiou, H. y Treuil, R. (eds.): Moudre et broyer. L'interprétation fonctionnelle de l'outillage de mouture et de broyage dans la Préhistoire et l'Antiquité. Paris: стнs, vol. I, pp. 69-80.

Haudricourt, A. G. (1987): La technologie, science humaine. Recherches d'histoire et d'ethnologie des techniques. Paris: Maison des Sciences de l'Homme.

Jardón, P.; Hortelano, L.; Bencomo, M.; Sirvent, L. y Aura, J. E. (2018): Estudio experimental y traceológico sobre piezas destinadas al trabajo de la madera (cuñas y azuelas) a través de réplicas de soportes paleolíticos y neolíticos", Butlleti Arqueologic, v, 40, pp. 209-217.

Márquez, A. M. (2005): "Análisis tecnológico de una pieza de arte mueble de la Cueva de Nerja (Málaga, España)", Zephyrus, LviII, pp. 135-158.

Neвот, A. (2007): "Morfopotencialidad de los percutores-retocadores del Nivel XIII de la cueva del Esquilleu (Cantabria)", Boletin de Arqueología Experimental, 7, pp. 45-53.

Pelegrin, J. (2000): "Les techniques de débitage laminaire au Tardiglaciaire: critères de diagnose et quelques réflexions". En Valentín, B.; Bodu, P. y Christensen, M. (eds.): L'Europe centrale et septentrionale au Tardiglaciaire. Confrontation des modèles régionaux de peuplement. Actes Table Ronde, Nemours, 1997. Mémoire du Musée de Préhistoire d'Ile-deFrance, 7. Nemours: APRAIF, pp. 73-86.

Peresani, M.; Bertola, S.; De Stefani, M. y Di AnasTASIO, G. (1999-2000): "Bus de la Lum and the Epigravettian occupation of the Venetian Pre-Alps during the Younger Dryas", Rivista di Science Preistoriche, L, pp. 103-132.

Raynal, J.-P.; Moncel, M.-H.; Daujeard, C.; Fernandes, P.; Fiore, I.; Tagliacozzo, A.; Lecorre-Le 
Beux, M.; Chacon Navarro, G. y TheodoropouLOU, A. (2012): "Neanderthal land-use and related tool-kits at the MIS 5/4 boundary in the South-East portion of the French Massif Central". En Ruebens, K.; Romanowska, I. y Bynoe, R. (eds.): Unravelling the Palaeolithic. Ten years of research at the Centre for the Archaeology of Human Origins (CAHO, Univ. of Southampton). BAR Intern. Ser., 2400. Oxford: Archaeopress.

SARI, L. (2015): "Les galets utilisés Ibérimaurusiens de l'abri de Tamar Hat (Béjaä, Algérie Nord-Orientale): analyse techno-fonctionelle et hypothèses palethnographiques". En Oueslati, A. (coord.): Actes $1^{\text {ére }}$
Rencontre ATEQ pour l'Étude du Quaternaire en Tunisie. Túnez: ATEQ, pp. 174-187.

Such, M. (1996): Avance al estudio de la caverna Hoyo de la Mina en Málaga. Málaga: Univ. de Málaga.

Zampetti, D.; Lemorini, C. y Massussi, M. (2007): "Art et vie quotidienne dans l'Épigravettien final: les galets utilisés de la Grotta della Ferrovia (Italie centrale)". En De Beaune, S. A. (dir.): Chasseurs-cueilleurs. Comment vivaient nos ancêtres au Paléolithique supérieur, Actes Colloque International "Restituer la vie quotidienne au Paléolithique supérieur" (Lyon, 2005). Lyon: CNRs, pp. 171-185. 
